\title{
Analysis of thermal degradation behavior for some hydraulic oils, using FTIR-TGA coupling
}

\author{
Niculina-Sonia Șuvar, Maria Prodan, Irina Vasilica Nălboc and Andrei Szollosi-Moța \\ National Institute for Research and Development in Mine Safety and Protection to Explosion, \\ INSEMEX Petroșani, 32-34 Gen. Vasile Milea Street, Petroșani, Romania
}

\begin{abstract}
The transitions between the vibrational energetic states of atoms represent the infrared absorption spectra, which is a band spectrum over which the transitions between energetic rotational states overlap.

One of the most important uses of infrared absorption spectrometry is the identification in quantitative terms of the structure of compounds from a substance, the analytes being either solid, liquid or vaporous.

The FTIR-TGA Coupling is a technique that permanently controls the mass loss in a sample, as a function of temperature and time, as well as the identification and recording of various compounds occurring during the combustion process.

Research on hydraulic oils has consisted of their analysis using the FTIRTGA coupling in order to identify flammable substances that can generate explosive events.
\end{abstract}

\section{Introduction}

Thermal analysis is a technique consisting in measuring the mass variation of a sample over a well-established temperature program, in a controlled atmosphere. Sample heating is performed at a constant speed set by a temperature program, the mass changes being measured with a very sensitive balance.

Changes in sample mass are of a physical nature (gas absorption/desorption, phase transitions (sublimation - vaporization), or chemical nature (decompositions, cleavage reactions, gas-phase reactions, chemical absorption) $[1,6]$.

IR spectroscopy is a classical technique which depends upon the interaction of infrared radiation with vibrating dipole moments of molecules. It provides, with the exception of homonuclear diatomics and noble gases, a characteristic spectrum for each substance [2].

FTIR spectra reveals the composition of solids, liquids and gases. One of the most common use is in the identification of unknown materials and confirmation of production materials, the information provided by this analysis being very specific in most cases. FTIR analysis is characterized by a remarkable speed, making it useful in screening applications.

The coupling between IR spectrometry by Fourier transformation (FTIR) and thermogravimetric analyzer (TGA) is a good example of practical analytical problemsolving. This technique provides quantitative information for identifying compounds resulting from the decomposition of the samples by combustion, namely the resulting gases $[4,5]$.

\footnotetext{
* Corresponding author: sonia.suvar@insemex.ro
} 
The gases are transferred from the TGA instrument using a heated transfer line to prevent the possibility of condensation. With such a combination, the sample can be inserted into the TGA instrument without any form of chemical or physical change. Applying sequential FTIR analysis adds a new TGA dimension by adding to the measurement the specificity it otherwise lacks [3].

Hydraulic oils play an important role in hydraulic systems and as a result, they have a number of properties and characteristics that recommend them for such a task. An important property is the flammability point, i.e. the temperature at which are created the vapors that can ignite in the presence of a thermal source. The combustion point and the self-ignition point are other thermal properties that define these types of oils.

Mineral oils are extracted from crude oil or coal, consisting of hydrocarbon mixtures. Hydrocarbons are stable at relatively low temperatures. When they are heated at fairly high temperatures for a sufficient period of time, the chains decompose, forming other lowerchain hydrocarbons, some of them having a flammable character [7, 8]. The decompositions can continue then to carbon and hydrogen.

These decomposition reactions give rise to other hydrocarbons with higher relative stability at high temperatures.

The thermal stability of the oil represents its ability to withstand the decomposition process, for the temperature threshold for which it is intended. Research on hydraulic oils has been carried out using the FTIR-TGA coupling in order to identify some flammable substances that can generate explosive events.

\section{Materials and methods}

Analysis of thermal degradation behavior was performed for two types of hydraulic oil, used in the technological processes of splinting, cutting, compacting of some metallic materials. Sample 1 (coded as GLP 46) has a flash point of $240{ }^{\circ} \mathrm{C}$ and a self-ignition temperature of $370{ }^{\circ} \mathrm{C}$. Sample 2 (coded as HLP 46) has a flash point of $209{ }^{\circ} \mathrm{C}$, respectively a self-ignition temperature of $360^{\circ} \mathrm{C}$.

The samples were analyzed using the Labsys Evo thermal analysis system coupled with a Fourier -Transform - Infrared (FTIR) spectrometer with Nicolet IS 50 TGA equipment, shown in Figure 1.

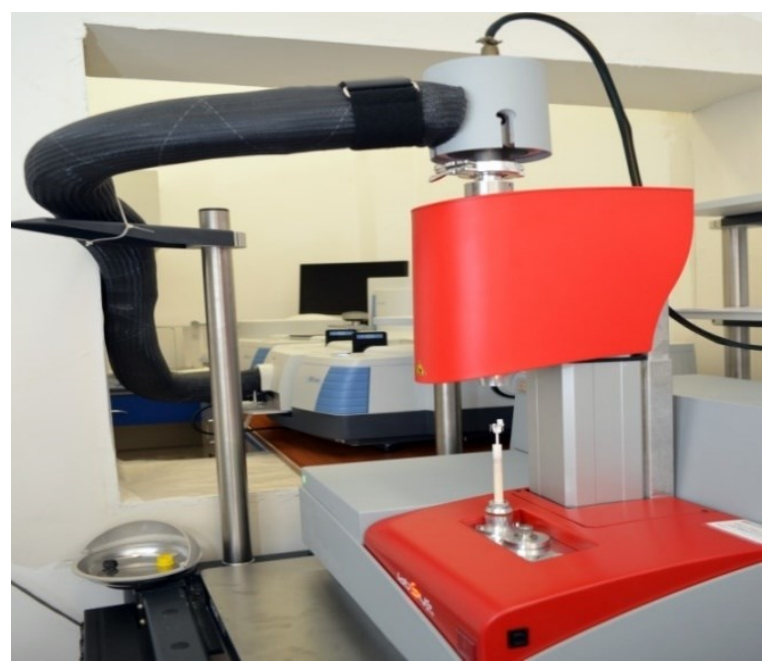

Fig. 1. Labsys EvoTermoderivatograph coupled with Nicoret IS 50 FTIR equipment, with included TGA module 
The TG module of the spectrometer was heated to $250{ }^{\circ} \mathrm{C}$ to avoid gas condensation. Helium was used as a carrier gas, at a flow rate of $30 \mathrm{ml} / \mathrm{min}$.

The temperature program for both samples started from $30{ }^{\circ} \mathrm{C}$ for $20 \mathrm{~min}$, increased then to $1000{ }^{\circ} \mathrm{C}$ for $97 \mathrm{~min}$ with an increasing ramp of $10{ }^{\circ} \mathrm{C} / \mathrm{min}$ and a stationary stage at $1000{ }^{\circ} \mathrm{C}$, for $20 \mathrm{~min}$. Cooling was done at $50^{\circ} \mathrm{C} / \mathrm{min}$, until $30^{\circ} \mathrm{C}$.

\section{Results and discussions}

As a result of the two samples analysis using the thermal analysis coupled with infrared spectrometry, the following TGA thermal analysis graphs were obtained (Figure 2):

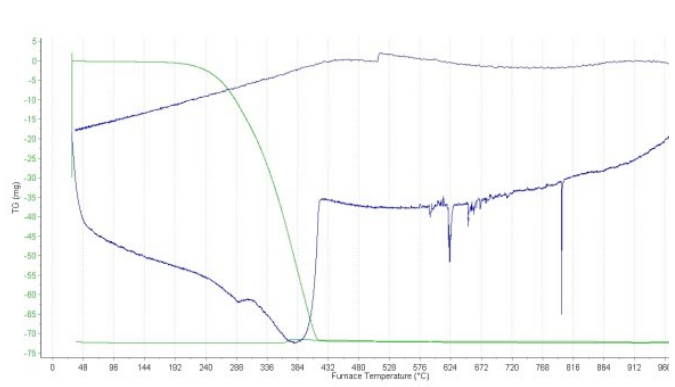

Legend: - Heat flow, - Mass change

Thermal analysis graph for sample no. 1

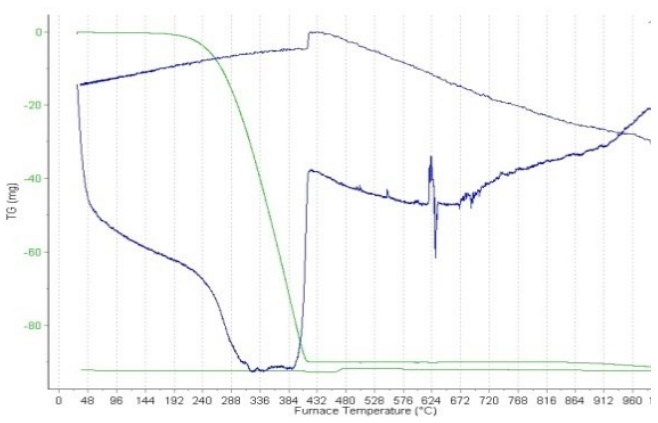

Legend: - Heat flow, - Mass change

Thermal analysis graph for sample no. 2

Fig. 2. TGA thermal analysis graphs obtained for the two analysed samples

Initial mass for sample no. 1 was $68.85 \mathrm{mg}$. Analyzing the TGA thermal analysis graph, we can observe to have a mass loss of $51.91 \mathrm{mg}$ in the temperature range of $198.00 \div$ $476.42{ }^{\circ} \mathrm{C}$.

Sample no. 2 had an initial mass of $87 \mathrm{mg}$, and by heating it by the set temperature program it was found that in the temperature range of $114,19 \div 407,25{ }^{\circ} \mathrm{C}$, a mass loss of $86.34 \mathrm{mg}$ occurred.

Identification of compounds resulting from burst samples decompositions was possible by Fourier Transform Infrared (FTIR) spectrometry using the TGA module resulting in the following spectra (Figure 3, a, b):
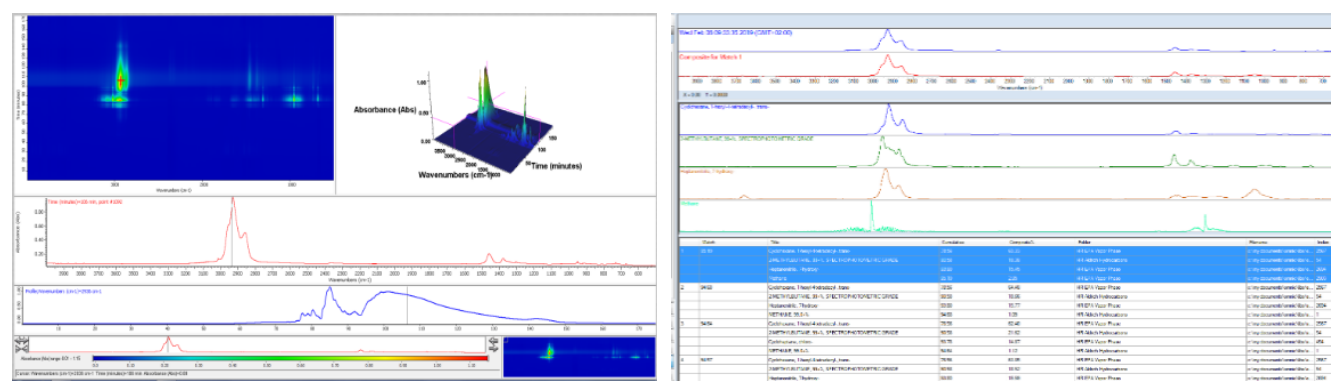

a) Spectra for Sample no. 1 

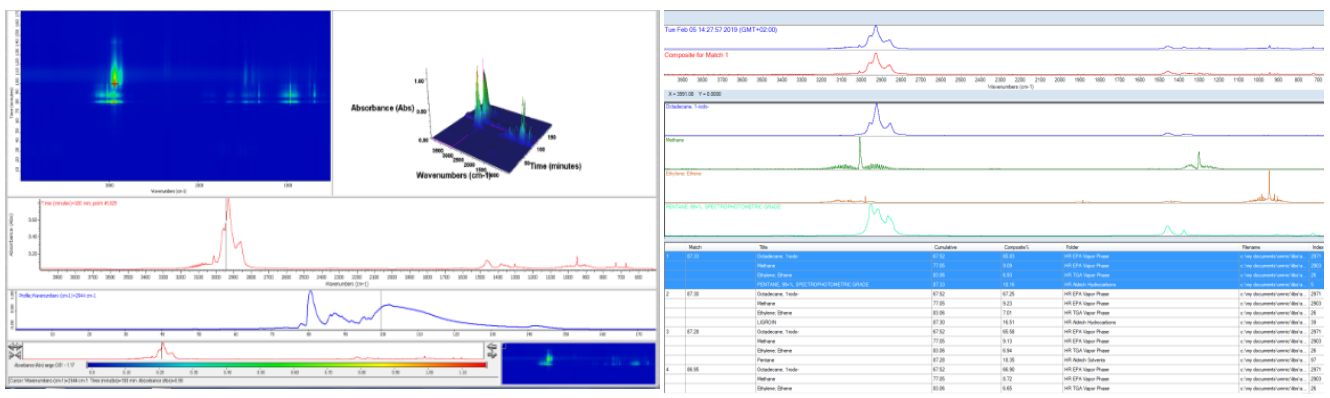

b) Spectra for Sample no. 2

Fig. 3. Spectra for sample 1 (a) and sample 2 (b)

These spectra have shown the existence of substances found in the composition of oils used in technological processes, namely: hexane, methane, ethene, cyclohexane, benzene, methyl butane, pentane etc.

To determine the period of explosive atmosphere forming danger, the volume of flammable vapors released in the technological process for the two oil samples was determined. The loss of mass resulting from the controlled burning of the oils analyzed was correlated with the gases resulting from the IR analysis.

It went from the initial data of each sample:

a. For sample no. 1 , initial data were: initial mass $=68.85 \mathrm{mg}$, remaining mass $=16.94$ $\mathrm{mg}$, consumed mass $=51.91 \mathrm{mg}$.

After 87 minutes, the following gases were identified: $38 \%$ methane, $43 \%$ ethene, $20 \%$ benzene.

Following calculations using gas law, the following gas volumes were obtained at 87 minutes: 0.007 liter methane, 0.004 liter ethene, 0.0007 liter benzene (Figure 4).

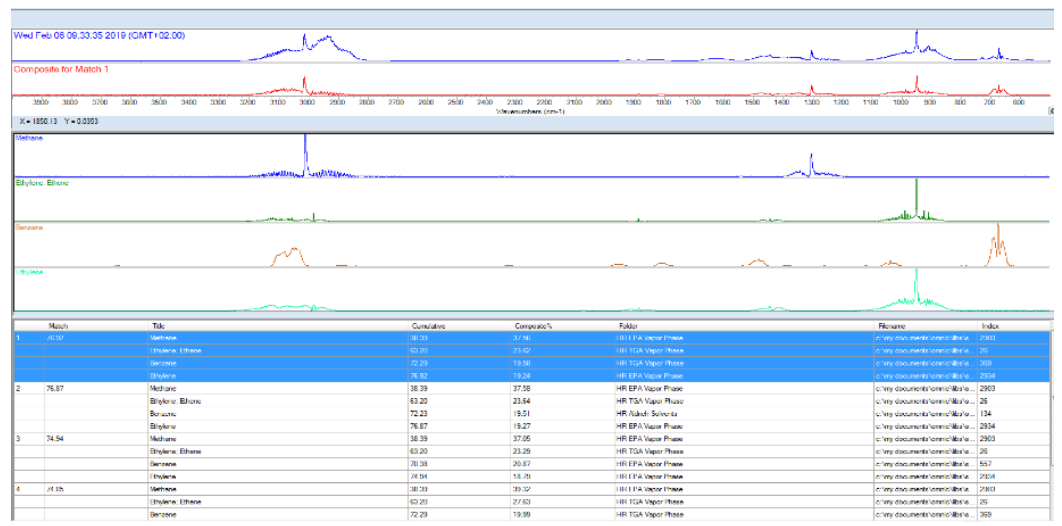

Fig. 4. Sample no. 1 spectrum at minute 87

At minute 106, the following gases were identified: $63 \%$ cyclohexane, $18 \%$ methyl butane, $3 \%$ methane, $15 \%$ hepta-nitrile.

After the calculations made using the gas law, the following gas volumes were obtained at 106 minutes: 0.002 liters Cyclohexane, 0.0005 liters Methane, 0.0007 liters Methyl butane and 0.0005 liters Hepta-nitrile (Figure 5). 


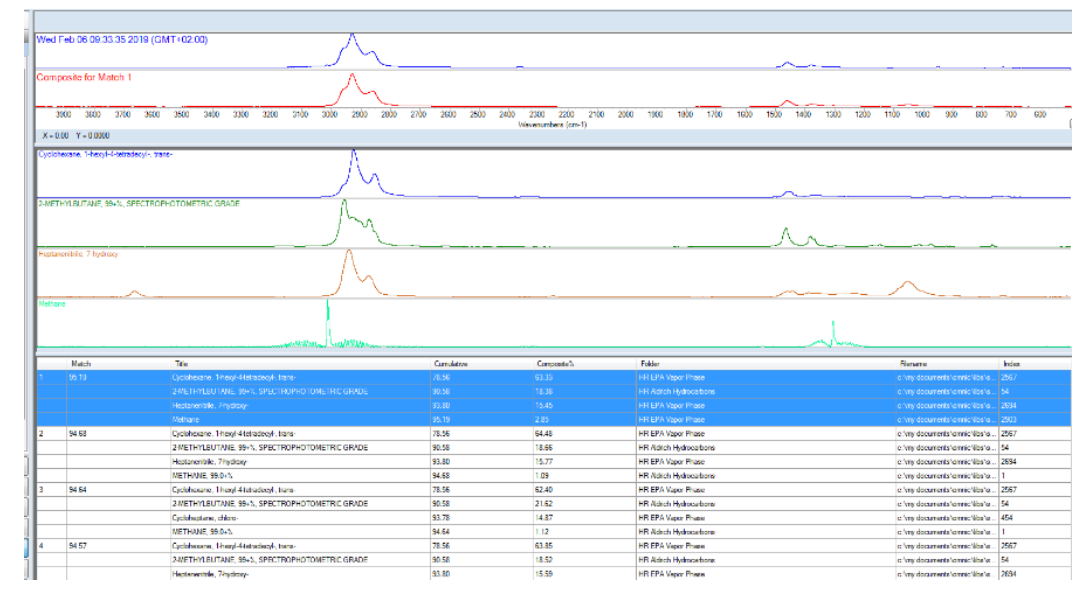

Fig. 5. Sample no. 1 spectrum at minute 106

The total gas mixture obtained at the decomposition of the GLP 46 oil sample $=0.0314$ liters, at $20^{\circ} \mathrm{C}$.

Using gas law and a temperature of $700{ }^{\circ} \mathrm{C}$ for sample no. $1,11.17 \mathrm{~m}^{3}$ of the flammable gas mixture were obtained, a mixture released in about 413 seconds (about 7 minutes), during which there is present the danger of explosive atmosphere.

About 15-20 minutes after the oil is introduced, at a temperature of $700-1000{ }^{\circ} \mathrm{C}$, a volume of $11.17 \mathrm{~m}^{3}$ of flammable vapors is released.

The minimum explosive concentration may be considered around $1 \%$, taking into account that most of the resulting compounds in the mixture have a lower explosion limit below $2 \%$, and the elevated temperature $\left(700-1000{ }^{\circ} \mathrm{C}\right)$ influences the lower limit in the direction of decreasing, the worst case resulting both from the tests performed and from the theory.

If the lower limit of the mixture is considered to be $1 \%$ volume, then a volume of $\mathrm{V}=$ $0.029 \mathrm{~m}^{3}$ of flammable vapors is generated at the airflow rate of $2.95 \mathrm{~m}^{3} / \mathrm{s}$ that is aspirated. Thus, if a volume of $0.0295 \mathrm{~m}^{3}$ of flammable vapor is released per second, a minimum explosive concentration of the mixture can be obtained.

b. For sample no. 2 , the initial data were the following: initial mass $=87 \mathrm{mg}$, residual mass $=0.66 \mathrm{mg}$, consumed mass $=86.34 \mathrm{mg}$.

When performing the analysis of the $2^{\text {nd }}$ sample, at minute 88 were been identified the following gases, obtained from the oil decomposition: methane $36 \%$, ethene $43 \%$, benzene $20 \%$.

After the calculations carried out using the gas law, the following gas volumes were obtained at minute 88: methane 0.009 liter, ethene 0.006 liter, benzene 0.001 liter (Figure $6)$. 


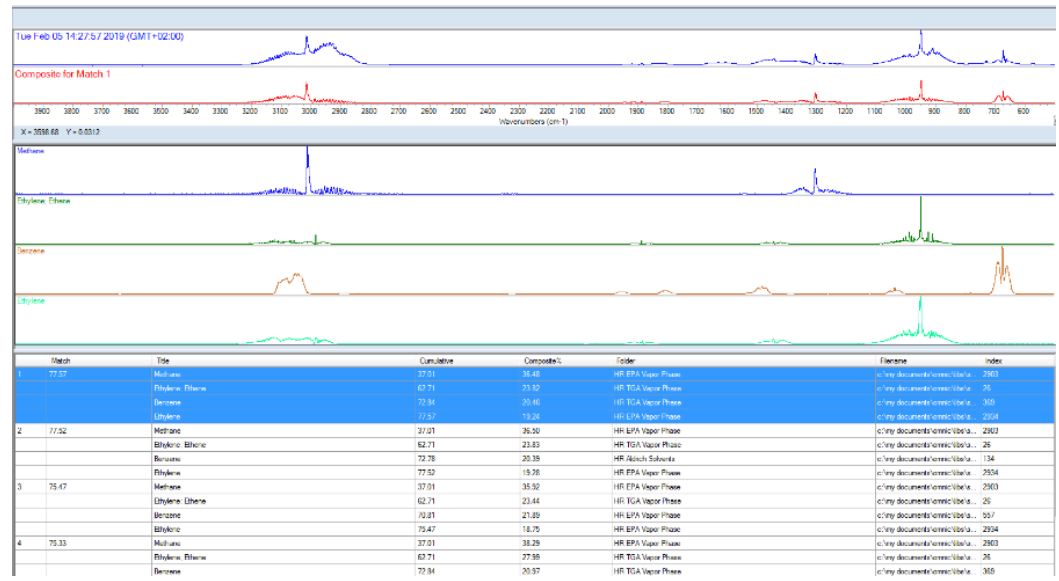

Fig. 6. Sample no. 2 spectrum at minute 88

When performing the analysis of the $2^{\text {nd }}$ sample, at minute 100 , the following gases were obtained after decomposition of the oil: $66 \%$ octadecane, $9 \%$ methane, $7 \%$ heptane, $18 \%$ pentane.

After the calculations carried out using the gas law, the following gas volumes were obtained at minute 100: octadecane 0.001 liter, methane 0.001 liter, ethene 0.001 liter, pentane 0.001 liter (Figure 7).

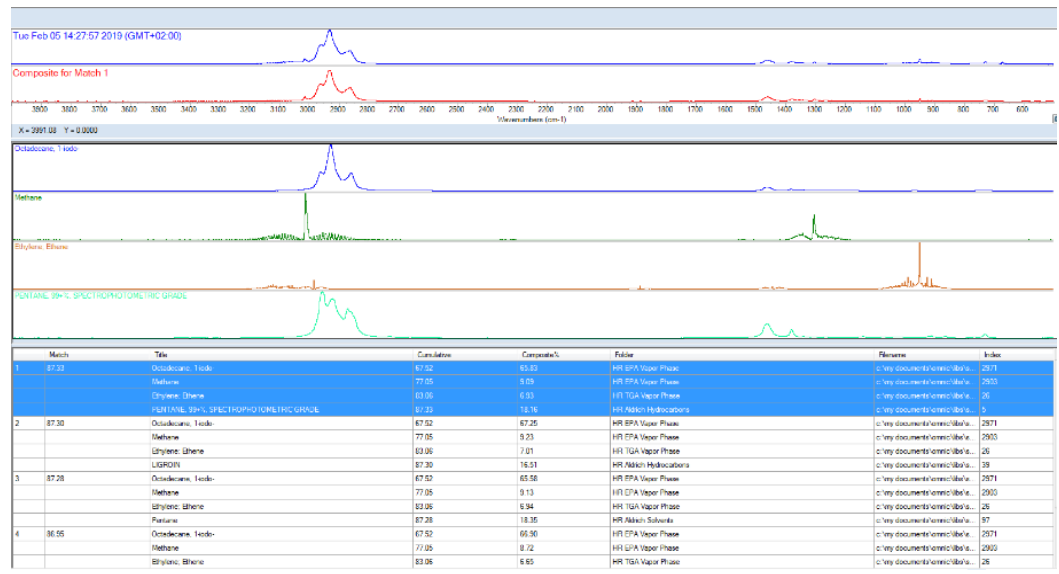

Fig. 7. Sample no. 2 spectrum at minute 100

The total gas mixture obtained at the decomposition of the HLP 46 oil sample $=0.042$ liters at $20^{\circ} \mathrm{C}$.

Using the gas law and a temperature of $700{ }^{\circ} \mathrm{C}$ for sample no. $2,8.98 \mathrm{~m}^{3}$ of flammable gas mixture were obtained, a mixture released in about 333 seconds (about 6 minutes), during which there is present the danger of explosive atmosphere. Approximately 15-20 minutes after the oil is introduced, a volume of $8.98 \mathrm{~m}^{3}$ of flammable vapors is released, at $700-1000{ }^{\circ} \mathrm{C}$.

The minimum explosive concentration can be approximated to $1 \%$, taking into account that most of the resulting compounds in the mixture have a lower explosion limit below $2 \%$, and the elevated temperature $\left(700-1000{ }^{\circ} \mathrm{C}\right)$ influences the lower limit in the direction of decreasing, the worst case resulting both from the tests performed and from the theory. 
If the lower limit of the mixture is considered to be $1 \%$ volume, then a volume of $\mathrm{V}=$ $0.029 \mathrm{~m}^{3}$ of flammable vapors is generated at the airflow rate of $2.95 \mathrm{~m}^{3} / \mathrm{s}$ that is aspirated. Thus, if a volume of $0.0295 \mathrm{~m}^{3}$ of flammable vapor is released per second, a minimum explosive concentration of the mixture can be obtained.

As it is known, a mixture of flammable gases has an explosive character in the range given by the lower explosion limit, respectively the upper explosion limit. In the present research, the interest was that the gas mixture obtained by the thermal decomposition of the studied oils does not reach the lower explosion limit. The lower explosion limit of a flammable gas mixture can be estimated by deriving the Le Chatelier principle.

The limits of the explosivity interval for the analyzed samples vary during the analysis, the identified gases after combustion being different, both in terms of concentration and composition, as it results through the spectrograms obtained at different time intervals.

\section{Conclusions}

The method of analysis using the TG - FTIR coupling has been found to be appropriate in identifying substances/compounds resulting from decompositions of samples through combustion, substances found in the composition of oils used in technological processes. Among these, we can mention:

- flammable substances that can cause unforeseen events;

- substances belonging to the class of hydrocarbons such as methane, ethane, hexane, cyclohexane, benzene, pentane, methyl butane etc.

These substances may become hazardous in terms of explosion risk, so that after identifying the hazard situation arising generated by these substances it is necessary to take measures to avoid the occurrence of undesirable events.

This paper was developed within the NUCLEU - Programme, carried out with the support of the Romanian Ministry of Research and Innovation - MCI, Project no. PN 19210103.

\section{References}

1. W.A. Herrera-Kao, M. I. Loria-Bastarrachea, Y. Perez-Padilla, J.V. Cauich-Rodriguez, H. Vasquez-Torres, J.M. Cervantes-Ue, Polymer Bulletin 75(9), 4193-4205 (2018)

2. A.T. Pemberton, D.B. Magers, D.A. King, J of Chemical Education 96(1), 132-136 (2019)

3. S. Materazzi, J Applied Spectroscopy Reviews 32(4), 385-404 (1997)

4. G.L. Radu, G.I. Truică, R. Penu, V. Moroeanu, S.C. Litescu, U.P.B. Sci. Bull., Series B 74(4), 137148 (2012)

5. A.H. Khan, M. Saiful, H.M. Imran, M.D. Yunus Miah, I. Rafiqul, DUJASE 2(1), 39-43 (2011)

6. G.R. Heal, Thermogravimetry \& Derivative Thermogravimetry (Principles of Thermal Analysis \& Calorimetry, P.J. Haines, Royal Society of Chemistry, Cambridge, 2002)

7. E.E. Klaus, J.M. Perez, Tribology Transactions 10(1), 38-47 (1967)

8. D.P. Nolan, Handbook of Fire and Explosion Protection Engineering Principles for Oil, Gas, Chemical, and Related Facilities, Fouth Edition (Elsevier - Gulf Professional Publishing, US, 2019). 